\title{
Effect of oral D-penicillamine treatment on experimental arthritis and associated immune responses in rabbits. III: Reduction of the monoarticular arthritis
}

\author{
I. M. HUNNEYBALL*, G. A. STEWART $\dagger$, AND D. R. STANWORTH \\ From the Department of Immunology, University of Birmingham, Birmingham
}

SUMMARY Treatment of rabbits with D-penicillamine at doses up to $30 \mathrm{mg} / \mathrm{kg}$, beginning either before or after the onset of antigen-induced experimental arthritis, diminished the severity of the inflammatory synovitis in a considerable proportion of animals as judged by both external joint measurements and terminal histopathological assessment. D-penicillamine treatment had no effect on serum haptoglobin concentration, haemoglobin concentration, or platelet count. The venous blood white cell count was raised when D-penicillamine treatment was started before immunisation but not when treatment began after the onset of arthritis. A transient loss of appetite was observed in animals starting D-penicillamine treatment.

Although the therapeutic value of D-penicillamine in the treatment of rheumatoid arthritis is now well established (Multicentre Trial Group, 1973; Day et al., 1974), its mode of action is unknown. The Dumonde and Glynn (1962) experimental arthritis model in rabbits is a chronic monoarticular disease which shows a very close resemblance histologically to rheumatoid arthritis (Glynn, 1968). Preliminary studies have shown that daily oral treatment of chronically arthritic New Zealand White (NZW) rabbits with low doses of D-penicillamine leads to a diminution of the chronic inflammatory reaction (Püschel et al., 1976; Hunneyball et al., 1977). However, short term treatment with high doses of D-penicillamine has been found to have no such effect in either Old English (OE) rabbits with Dumonde and Glynn experimental arthritis (Blackham and Radziwonik, 1977) or Sprague-Dawley rats with adjuvant arthritis (Liyanage and Currey, 1972).

D-penicillamine treatment of rabbits has been found to inhibit the production of IgG antibodies in

Accepted for publication 12 May 1978

Correspondence to Dr D. R. Stanworth.

*Present address: Research Department, The Boots Company Ltd., Nottingham NG2 3AA.

†Present address: Clinical Immunology Unit, Department of Microbiology, Princess Margaret's Hospital, Perth, Western Australia. response to immunisation with ovalbumin and reduce the delayed hypersensitivity response of the animals to both ovalbumin and tuberculin PPD (Hunneyball et al., 1978a). Furthermore a stimulation of macrophage function was also observed in these animals. We have therefore investigated further the effect of D-penicillamine treatment on both the acute and chronic phases of the monoarticular arthritis when treatment with the drug was started either before or after the onset of the arthritis. An impressive reduction in the inflammatory joint reaction was observed in animals treated with $\mathrm{D}$ penicillamine, particularly when treatment began before immunisation.

The results are discussed in relation to the previously reported immunosuppressive effects of $D$ penicillamine in these animals. In this way this study has provided a clearer understanding of the mode of action of D-penicillamine in alleviating chronic arthritic conditions. It also suggests that the Dumonde and Glynn experimental arthritis model is worthy of further exploitation in investigating the mode of action of other antirheumatic drugs.

\section{Materials and methods}

INDUCTION OF ARTHRITIS

34 commercially obtained (OLAC, (Oxfordshire Laboratory Animal Colonies) 1976) New Zealand White/ 
Californian crossed rabbits of either sex, weighing 3-4 kg, were used in this study. Arthritis was induced in 1 knee of each animal according to the method of Dumonde and Glynn (1962) with thrice crystallised ovalbumin (Sigma Ltd.) being used as antigen (Consden et al., 1971). The animals were immunised by subcutaneous injection of ovalbumin (10 $\mathrm{mg}$ in $0.5 \mathrm{ml}$ sterile saline) emulsified with an equal volume of complete Freund's adjuvant (Difco) into the interscapular region at 4 sites $(0.25 \mathrm{ml}$ per site). The injections were repeated 14 days later, and after a further 10 days the animals were tested for delayed hypersensitivity by intradermal injection of 10,30 , and $50 \mu \mathrm{g}$ of ovalbumin in $0.1 \mathrm{ml}$ sterile saline. The erythema diameters were measured 24 and 48 hours after initial challenge. 30 days after testing, ovalbumin $(10 \mathrm{mg}$ in $0.5 \mathrm{ml}$ sterile saline) was injected into the right knee of each animal, the left knee being injected with $0.5 \mathrm{ml}$ sterile saline as a control.

\section{D-PENICILLAMINE TREATMENT}

Both the dose and the route of administration of Dpenicillamine were chosen to correspond to those used in the treatment of human rheumatoid arthritis, namely, $15-30 \mathrm{mg}$ D-penicillamine per $\mathrm{kg}$ body weight orally per day (approximately equivalent to a dose of $1 \mathrm{~g}$ per day for a $70 \mathrm{~kg}$ patient). The dry D-penicillamine powder (Distamine) was administered daily by mouth in gelatin capsule form. Fifteen animals were used as controls and 19 treated with D-penicillamine as outlined in Table 1 . When D-penicillamine treatment was started after the onset of the arthritis, each treated animal was compared with a control animal matched according to the degree of swelling of the arthritic joint before the beginning of treatment.

\section{MEASUREMENT OF JOINT DIMENSIONS}

The circumference and width of both knee joints of each rabbit were measured with a tensioned cali-

Table 1 D-penicillamine treatment regimens. All dates are given as days relative to the date of intra-articular injection. Numbers in parentheses indicate the number of animals surviving till the end of the experiment

\begin{tabular}{|c|c|c|c|c|}
\hline \multirow[t]{2}{*}{ Group } & \multirow{2}{*}{$\begin{array}{l}\text { No. of } \\
\text { animals }\end{array}$} & \multicolumn{3}{|c|}{ Date relative to intra-articular injection } \\
\hline & & $\begin{array}{l}\text { Treatment } \\
\text { commenced } \\
\text { at } 15 \mathrm{mg} / \mathrm{kg}\end{array}$ & $\begin{array}{l}\text { Dose } \\
\text { increased } \\
\text { to } 30 \mathrm{mg} / \\
\mathrm{kg}\end{array}$ & $\begin{array}{l}\text { Animals } \\
\text { Killed }\end{array}$ \\
\hline $\begin{array}{l}\text { 1-Treated } \\
\text { 1-Control } \\
\text { 2-Treated } \\
\text { 2-Control }\end{array}$ & $\begin{array}{r}7 \\
7 \\
12 \\
8\end{array}$ & $\begin{array}{l}+115 \\
-120\end{array}$ & $\begin{array}{l}+225 \\
+50\end{array}$ & $\begin{array}{l}+325(6) \\
+325(7) \\
+120(9) \\
+120(6)\end{array}$ \\
\hline
\end{tabular}

brated tape and engineering calipers respectively The degree of swelling was expressed as the ratio of the circumference (or width) of the antigen-injected (right) knee joint to that of the control saline-injected (left) knee joint. Measurements were taken at weekly intervals.

\section{HISTOLOGY}

Soft tissue specimens for histological examination were fixed in formal saline, embedded in paraffin wax, and sectioned at $5 \mu \mathrm{m}$. Calcified tissue speci $\vec{\omega}$ mens were decalcified in $10 \%$ disodium EDTAO solution at room temperature, assessed monthly by $x$-ray analysis, and finally double embedded andw sectioned. Sections were stained with either Ehrlich' haematoxylin and eosin or Van Giesen's stain.

\section{ASSESSMENT OF ARTHRITIS}

The animals were killed and the joint space of eachknee was immediately rinsed with $0.2 \mathrm{ml}$ sterile saline, and the resulting fluid was retained fot differential white cell counting. Half of each infra $\overrightarrow{0}$ patellar fat pad was removed, fixed, embedde ఝु separately, and sectioned. The remainder was removed still attached to the patellar tendon and sectioned after decalcification in EDTA. The remains ing portion of the joint was decalcified in EDTA and sectioned in the coronal plane. In each case section? were cut at 3 different levels through the tissue? Macroscopic observations of the exposed joint were $\overrightarrow{\overrightarrow{0}}$ recorded and the degree of erosion of cartilage and bone assessed blind and graded as follows: - ne erosive changes; +erosion of cartilage only; ++ as. for + with limited areas of bone erosion of femoraఖ condyles; +++ as for + with large areas of bone erosion of femoral condyles; ++++ as fo +++ but with erosion of intercondylar fossa and patella.

The intensity of inflammation of the synovium was assessed blind and graded in a similar manner to that described by Consden et al. (1971): - normat synovium; \pm normal synovium except for the occasional plasma cell; + sparse scattering of plasma cells and lymphocytes; ++ heavier infilo tration of plasma cells and lymphocytes with villous hyperplasia; +++ heavier cellular infiltration of virtually the whole synovium with denser areas of infiltration in places; ++++ very dense cellular infiltration of the entire synovium.

HAEMATOLOGICAL DATA

Erythrocyte, leucocyte (total and differential), and platelet counts were kindly performed at week intervals by the Department of Haematolog? Queen Elizabeth Hospital, Birmingham, by courtesy of Dr J. Stuart. 


\section{HAPTOGLOBIN DETERMINATIONS}

Serum haptoglobin concentration was measured by the method of Ratcliff and Hardwicke (1964), and expressed as haemoglobin-binding capacity in $\mathrm{mg} /$ $100 \mathrm{ml}$ serum.

\section{MISCELLANEOUS MEASUREMENTS}

Urine samples were collected periodically for analysis using Labstix (Ames) and 3\% sulphosalicylic acid. Owing to the alkalinity of rabbit urine the samples were adjusted to $\mathrm{pH} 7 \cdot 0$ with $\mathrm{HCl}$ before analysis.

Animals were fed a pelleted diet ad libitum, and the weight of food eaten by each animal was recorded daily.

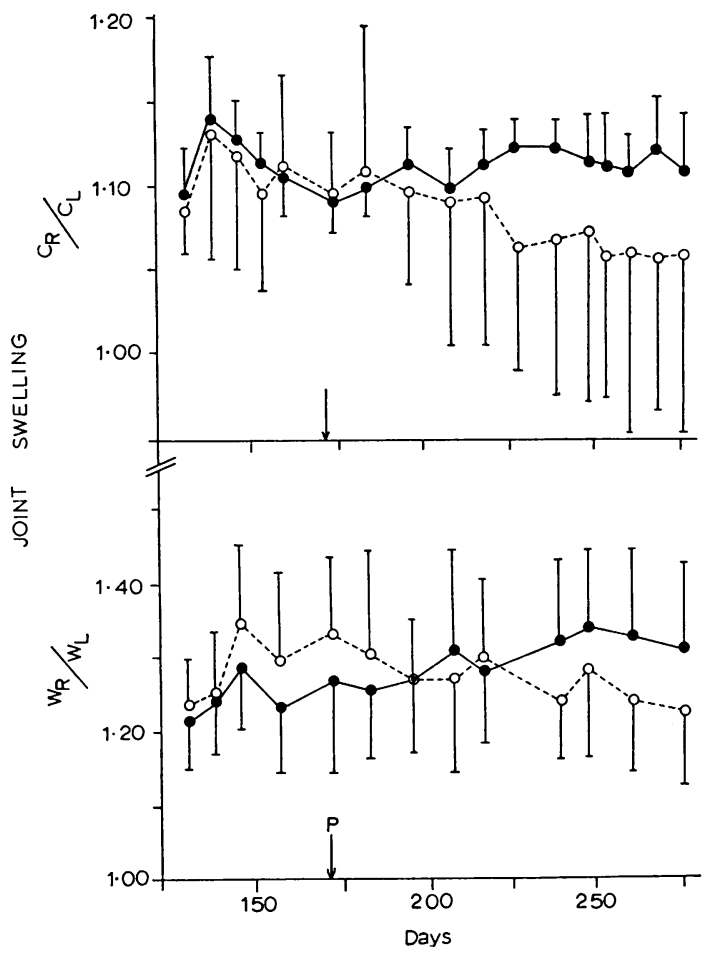

Fig. 1 The effect of oral D-penicillamine treatment, beginning 115 days after the onset of arthritis (arrowed) on the circumference (A) and width (B) of the inflamed knee joint of monoarticular arthritic animals of group 1. Immunisation began on day 0 , arthritis was induced by intra-articular injection of antigen on day 56. Results are expressed as the ratio of the circumference or width of the inflamed joint to that of the control joint. The solid line indicates untreated animals. Each point represents the mean of 7 animals. One standard deviation is shown for each point.

\section{Results}

TREATMENT BEGINNING AFTER ONSET OF CHRONIC ARTHRITIS (GROUP 1)

Before treatment animals were paired according to the width and circumference of the inflamed joint, 1 animal from each pair being treated daily with D-penicillamine. After treatment for approximately 50 days the mean circumference of the inflamed joints of the D-penicillamine treated group of animals decreased (Fig. 1A) and stayed at this reduced level until the animals were killed. However, this decrease was not statistically significant owing to the large standard deviation, arising from the fact that some animals showed no discernible decrease in circumference during treatment. This phenomenon was reflected in the terminal histopathological assessment (Table 2), which showed that some D-penicillaminetreated animals still had a chronic active synovitis similar to that of the matched control animal (pairs $\mathrm{F}$ and $\mathrm{G}$ ), whereas some animals showed complete remission (pairs A and B) with the remaining treated animals showing partial remission. It should be noted that although there was a general agreement between the joint circumference measure-

(A) ments and terminal histopathology, there were some exceptions (for example, pair F, treated). There did not appear to be any correlation between the magnitude of the swelling before the start of treatment and the degree of reduction in swelling resulting from D-penicillamine. In addition it is of interest that, although some reduction in the width of the inflamed joints of certain treated animals was

Table 2 Terminal assessment of histopathology of arthritic rabbits treated with D-penicillamine for 210 days commencing 16 weeks after the onset of arthritis

(B)

\begin{tabular}{|c|c|c|c|c|c|}
\hline Pair & $\begin{array}{l}\text { Treat- } \\
\text { ment }\end{array}$ & $\begin{array}{l}\text { Post- } \\
\text { treat- } \\
\text { ment } 1 \\
\text { swelling } \\
(\mathrm{mm})\end{array}$ & $\begin{array}{l}\text { Synovial } \\
\text { inflammation } \\
\begin{array}{l}(-\overrightarrow{+} \\
+++)\end{array}\end{array}$ & $\begin{array}{l}\text { Erosion } \\
(-\rightarrow \\
++++)\end{array}$ & Response \\
\hline $\mathbf{A}$ & $\begin{array}{l}\mathrm{C}^{2} \\
\mathrm{~T}\end{array}$ & $\begin{array}{l}11 \\
-4\end{array}$ & $+1++$ & \pm++ & \pm \\
\hline \multirow[t]{2}{*}{ B } & C & 9 & ++ & ++ & \\
\hline & $\mathbf{T}$ & 0 & + & + & $\ddagger$ \\
\hline C & C & 21 & $\begin{array}{l}++ \\
++\end{array}$ & +++ & t \\
\hline \multirow[t]{2}{*}{ D } & C & 8 & $+++t$ & $\begin{array}{l}++ \\
++\end{array}$ & 1 \\
\hline & $\mathbf{T}$ & 13 & ++ & ND & $\dagger$ \\
\hline \multirow[t]{2}{*}{$\mathbf{E}$} & C & 13 & ++ & ++++ & \\
\hline & $\mathbf{T}$ & 4 & $+1++$ & +++ & $\dagger$ \\
\hline \multirow[t]{2}{*}{$\mathbf{F}$} & C & 7 & + & + & \\
\hline & $\mathbf{T}$ & $\mathbf{0}$ & + & + & * \\
\hline \multirow[t]{2}{*}{ G } & C & ND & $+1++$ & +++ & \\
\hline & $\mathbf{T}$ & 5 & 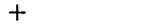 & +++ & * \\
\hline
\end{tabular}

1Difference in circumference between left and right knees before killing. ${ }^{2} \mathrm{C}=$ control, $\mathrm{T}=\mathrm{D}$-penicillamine-treated.

†Definite response to treatment. †Possible response to treatment. No response to treatment. ND $=$ Not determined. 
observed, the difference between the 2 groups was not statistically significant (Fig. 1B).

In all the control (untreated) animals the chronic synovitis persisted until the end of the experiment (325 days after infra-articular injection). Histological examination of the infrapatellar fat pads of these animals (Fig. 2) revealed an enlarged fat pad with villous hyperplasia of the synovial lining cells. Collagenous fibrous deposits were evident throughout the whole of the synovium, with diffuse mononuclear cellular infiltration near the articular surface and areas of dense cellular infiltration particularly in the villi. The deeper layers of the synovium contained predominantly fibroblasts. There was some variation in intensity of cellular infiltration between different areas of the synovium,
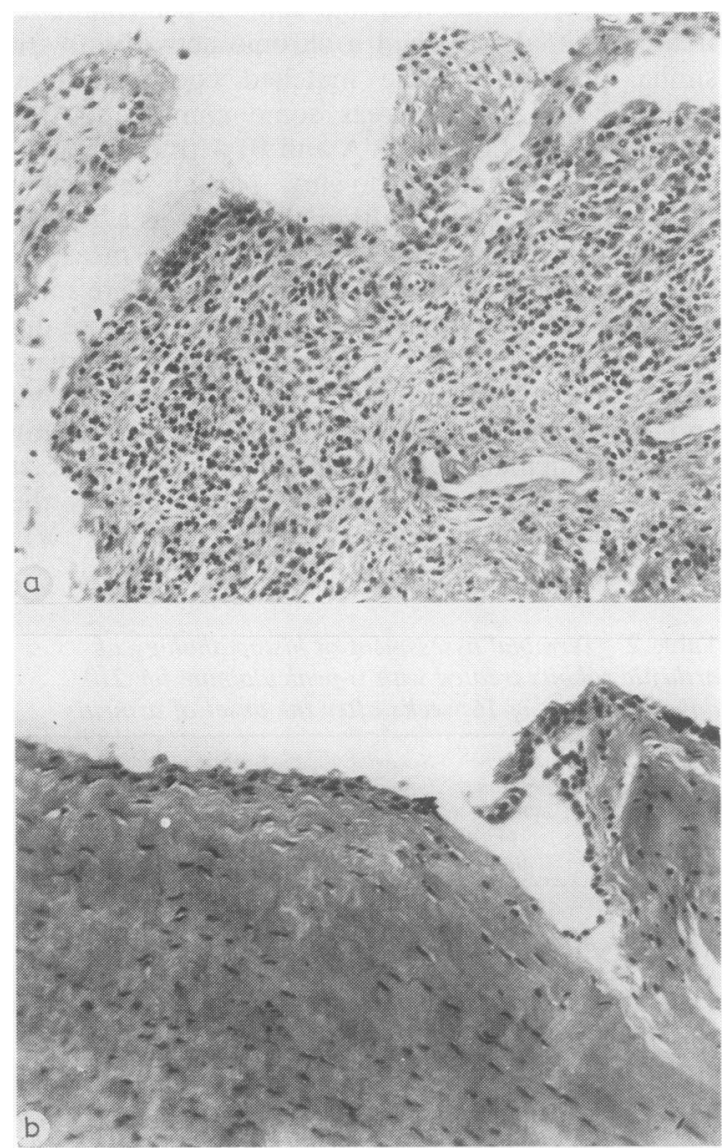

Fig. 2 Transverse sections through the articulating surface of the infrapatellar fat pad of the inflamed knee joint from group 1 chronic arthritic rabbits: (a) untreated animals, (b) animal treated with D-penicillamine for 210 days after the establishment of chronic arthritis. Haematoxylin and eosin, $\times 70$. which was reflected in the inflammatory gradings However, there was very little difference between the sections cut at the 3 different levels. Those $\mathrm{D} \stackrel{\text { S }}{\text { S }}$ penicillamine-treated animals appearing to respon $\Phi$ to the drug had fat pads of normal size with les로․ fibrosis than those of untreated animals. There was virtually no villous hyperplasia of the lining cells no generalised cellular infiltration, and only smalle very limited, areas of mononuclear cell infiltration-

Serum haptoglobin levels of untreated chronie arthritic animals were only slightly raised above normal. D-penicillamine treatment appeared to have no consistent effect on serum haptoglobin level Similarly, D-penicillamine appeared to have nô significant effect on haemoglobin concentration white cell count, or platelet count.

TREATMENT BEGINNING BEFORE

IMMUNISATION (GROUP 2)

Daily treatment of animals with D-penicillamine starting 120 days before intra-articular injectio

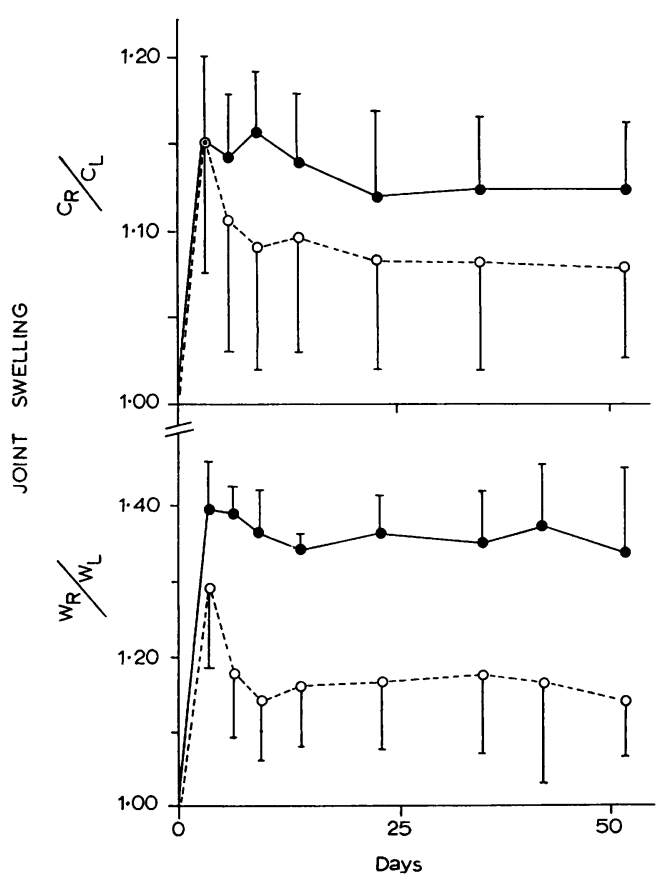

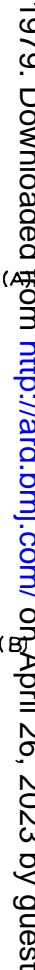

Fig. 3 The effect of oral D-penicillamine treatment, beginning 14 days before immunisation, on the circumference (A) and width (B) of the inflamed kne joint of monoarticular arthritic rabbits of group 2. Result are expressed as the ratio of the circumference or width of the inflamed joint to that of the control joint. The solid linêे indicates untreated animals; the broken line indicates D-penicillamine-treated animals. Each point represents the mean of 5 animals. One standard deviation is indicated. 
caused a significant reduction $(P<0.01)$ in the swelling of the antigen-injected joint as judged by width measurements (Fig. 3B). Similar reductions in circumference were also observed (Fig. 3A), but these were not statistically significant. As was found previously (group 1), the standard deviations of the $D$ penicillamine-treated group were greater than those of the control group, indicating different degrees of response to the drug. Furthermore, terminal histopathological assessment (Table 3) showed that some D-penicillamine-treated animals still had a chronic active synovitis, though these animals were in the minority (3 out of 9). As was found with group 1 , the reduction in intensity of synovial inflammation was accompanied by a reduction in the degree of erosion.

Terminal histological examination of the infrapatellar fat pads of untreated arthritic animals (performed 120 days after intra-articular injection) disclosed a hypervascular synovium with villous hyperplasia of lining cells, and considerable fibrosis together with quite heavy cellular infiltration (predominantly mononuclear in type) throughout the synovium, with large areas of dense cellular infiltration. In contrast, the fat pads of Dpenicillamine-treated animals contained far less fibrosis and still retained a considerable adipose
Table 3 Terminal assessment of histopathology of arthritic rabbits in which treatment with D-penicillamine began before immunisation together with corresponding treated control arthritic animals. For explanation of grading see 'Materials and methods'.

\begin{tabular}{|c|c|c|c|c|}
\hline Group & No. & $\begin{array}{l}\text { Synovial } \\
\text { inflammation } \\
\begin{array}{l}(-\rightarrow \\
++++)\end{array}\end{array}$ & $\begin{array}{l}\text { Erosion } \\
(-\rightarrow \\
++++)\end{array}$ & Response \\
\hline Control & $\begin{array}{l}1 \\
2 \\
3 \\
4 \\
5 \\
6\end{array}$ & $\begin{array}{l}+ \\
+ \\
++++ \\
++ \\
++ \\
+1++\end{array}$ & $\begin{array}{l}+ \\
+ \\
+++ \\
++++ \\
++ \\
++\end{array}$ & \\
\hline $\begin{array}{l}\text { D-penicillamine } \\
\text { treated }\end{array}$ & $\begin{array}{r}7 \\
8 \\
9 \\
10 \\
11 \\
12 \\
13 \\
14 \\
15 \\
\end{array}$ & $\begin{array}{l}+ \\
++ \\
- \\
+1++ \\
++1+++ \\
\pm \\
++ \\
+\end{array}$ & $\begin{array}{l}+ \\
+ \\
++ \\
+ \\
++ \\
++ \\
- \\
-\end{array}$ & $\begin{array}{l}\dagger \\
\ddagger \\
* \\
\ddagger \\
* \\
* \\
\ddagger \\
\dagger \\
\ddagger\end{array}$ \\
\hline
\end{tabular}

‡Definite response to treatment. †Possible response to treatment. ${ }^{*}$ No response to treatment.

tissue content. Very little villous hyperplasia was present and very little cellular infiltration was apparent. The active synovitis present in some D-penicillamine-treated animals appeared

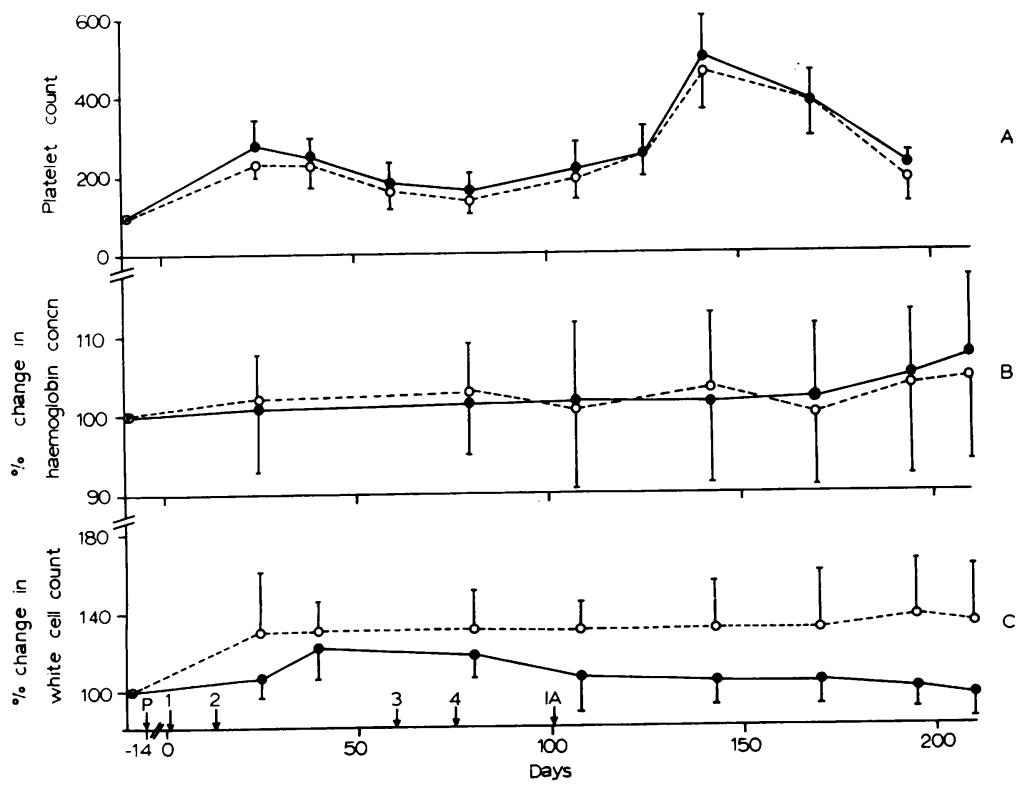

Fig. 4 Platelet count (thousands/ $\mu l$ ) and change in white cell count and haemoglobin concentration (expressed as percentage of pretreatment value) in untreated rabbits (solid line) and rabbits in which treatment with D-penicillamine began before immunisation. $P$ denotes start of D-penicillamine treatment. Arrows 1 to 4 denote immunising injections. IA denotes intra-articular injection. Each point represents the mean of 6 (untreated) or 9 (treated) animals. One standard deviation is indicated. Only those animals surviving the course of the experiment are included. 
histologically similar to that of untreated animals in all respects.

Serum haptoglobin levels rose in both untreated and D-penicillamine-treated animals as a result of both immunisation and intra-articular injection, there being no significant difference between the 2 groups. Similarly, D-penicillamine treatment appeared to have no effect on haemoglobin concentration or platelet count (Fig. 4). However, the white cell count rose (as a result of immunisation) to higher levels in D-penicillamine-treated animals than in untreated animals and did not decrease after intra-articular injection, resulting in a significant difference $(P<0.05)$ between treated and untreated groups of animals.

\section{SIDE EFFECTS}

Six animals died during the course of the experiment: 2 controls and 4 D-penicillamine-treated animals. Of these, the group 1 D-penicillamine-treated animal had a consistently falling haemoglobin level before death, reaching $70 \%$ of its starting value. The 2 untreated animals of group 2 and 2 D-penicillaminetreated animals died as a result of intra-articular bleeding during the acute phase of the arthritis. The other D-penicillamine-treated animal died during the immunisation phase from no obvious cause.

A loss of appetite was observed in both normal and arthritic rabbits on commencement of Dpenicillamine treatment (Fig. 5). The decrease in appetite of chronic arthritic rabbits beginning Dpenicillamine treatment lasted for 5-10 days, after which their appetite increased to a level higher than that of untreated arthritic animals. These changes were reflected in the weight of the animals. There was a transient fall in the weight of these animals (mean decrease $200 \mathrm{~g}$ ) detectable 2 weeks after starting treatment. The weight returned to pretreatment values after a further 4 weeks; there were no further changes after this time.

Animals treated with D-penicillamine before immunisation (group 2) had a reduced appetite during the immunisation phase. However, after intra-articular injection their appetite rose to a higher level than that of untreated animals. Before intra-articular injection the weight gain of these treated animals decreased, and eventually there was a net weight loss; whereas the weight of the untreated animals continued to rise. After intra-articular injection, when the weight of all of the animals fell, the mean decrease in weight of the D-penicillamine-treated animals $(118 \mathrm{~g})$ was only half that of the controls $(234 \mathrm{~g})$. Subsequently the weight of the treated animals rose at a faster rate than that of the controls, and 10 weeks after intra-articular injection both groups of animals had similar weights.

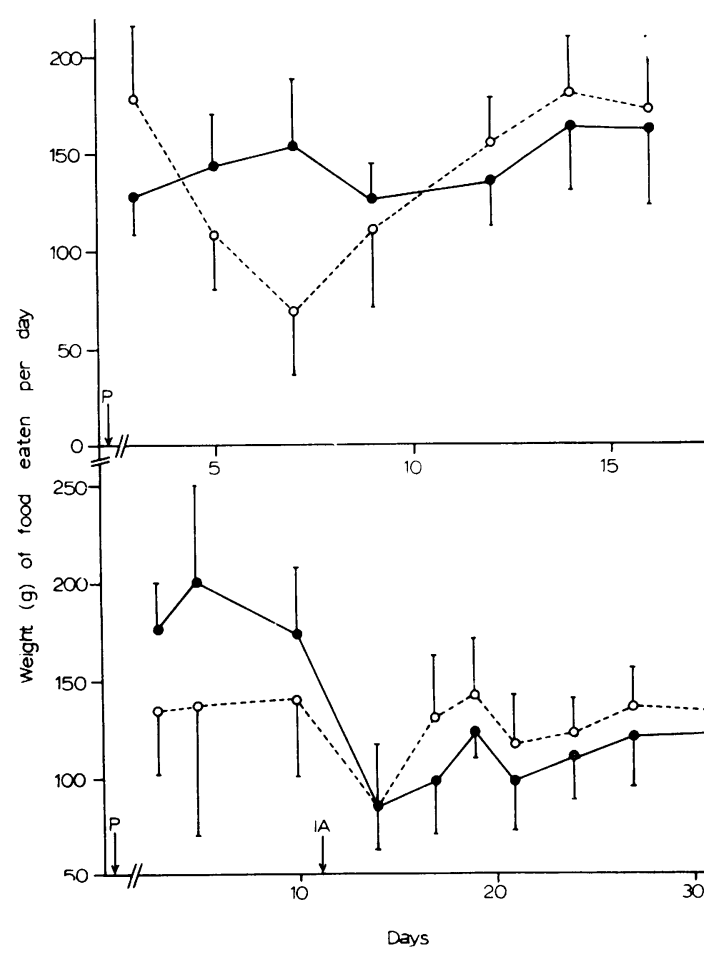

Fig. 5 Food consumption of: (A) group 1 chronic arthritic animals beginning D-penicillamine treatment; $(B)$ group 2 animals, in which treatment started before immunisation, monitored during the induction of the arthritis. $P$ denotes start of $\mathrm{D}$-penicillamine treatment. $1 A$ denotes intra-articular injection. Each point represents the mean of 5 animals. One standard deviation is indicated. The solid line indicates untr zated animals and and the broken line treated ones

Five of the 19 D-penicillamine-treated animals had proteinuria detectable by Labstix at the $30 \mathrm{mg}$ $100 \mathrm{ml}(300 \mathrm{mg} / \mathrm{l})$ level after treatment for $20 \notin$ days or more. However, proteinuria could bê detected in only one of these animals with sulphosalicylic acid. In contrast, only 1 of the 15 untreated animals showed significant proteinuria $(30 \mathrm{mg}$ $100 \mathrm{ml}$ ) by Labstix but not with sulphosalicylic acid? There were no overt pathological signs on exami을 nation of kidney sections of any of these animals bed light microscopy after staining with haematoxylin and eosin.

Four D-penicillamine-treated animals develope abcesses around the eyes during the course of treatment. These were found to contain Pasteurell 8 septicus and Staphylococcus aureus. No abcesse? were observed on untreated arthritic animals. 


\section{Discussion}

We have shown that prolonged daily oral treatment of rabbits with D-penicillamine at a dose of 15-30 $\mathrm{mg} / \mathrm{kg}$ beginning 16 weeks after the onset of chronic monoarticular arthritis can reduce the severity of the chronic synovitis in a considerable proportion of animals, as judged by both joint circumference measurements and terminal histopathological assessment. Treatment with higher doses of D-penicillamine $(100-200 \mathrm{mg} / \mathrm{kg}$ ) over shorter periods of time (up to 7 weeks) has recently been shown to be ineffective in Old English rabbits (Blackham and Radziwonik, 1977). This finding is in agreement with the 50-day delay observed by us before any diminution of the joint circumference could be detected. In addition it was observed that when treatment with D-penicillamine was started before immunisation a greater proportion of animals showed decreased synovitis as judged by both external joint measurements and terminal histopathological assessment.

The variation in response of arthritic rabbits to treatment with D-penicillamine is similar to that observed in D-penicillamine-treated patients with rheumatoid arthritis (Jaffe, 1970) and may be due to individual variation in absorption and hence plasma concentrations of the drug.

The measurement of joint circumference takes into account muscular swelling as well as joint effusion, whereas measurements of width take into account only the joint effusion and resulting lateral displacement of the menisci. Thus according to circumferential measurements during the acute phase of the arthritis changes in the degree of joint effusion can be masked to a certain extent by muscular swelling, which in this particular instance appeared to be unaffected by treatment with $D$-penicillamine. During the chronic phase of the arthritis, when there was no muscular swelling, the increased width of the inflamed joint appeared to be mainly due to the displacement of the menisci and unrelated to the effusion within the joint. Thus, when treatment with D-penicillamine reduced the visible joint effusion, the circumference of the joints decreased but the width remained virtually unchanged. It is possible, therefore, that in late chronic experimental arthritis the lateral displacement of the menisci may be irreversible.

The increase in the leucocyte count after treatment with D-penicillamine beginning before immunisation, but not after the onset of arthritis, may be related to the inhibition of specific antibody synthesis also observed under these conditions (Hunneyball et al., 1978a). However, these effects seem to be unrelated to the effect of the drug on the chronic arthritis, where similar effects can be seen under both treatment regimens.

The increase of serum haptoglobin concentrations in untreated experimentally arthritic rabbits was restricted solely to the acute phase of the arthritis and was unaffected by D-penicillamine treatment. In contrast, haptoglobin concentrations in the serum of patients with rheumatoid arthritis remain raised during the chronic disease and do decrease to a certain extent on treatment with D-penicillamine (Constable et al., 1975). It is of interest to note that the loss of taste reported by patients with rheumatoid arthritis during the first 3 months of treatment with D-penicillamine (Huskisson et al., 1974) has a counterpart in this experimental model in that a transient loss of appetite was observed in animals beginning $D$-penicillamine treatment.

The reduction in synovitis observed here as a result of D-penicillamine treatment is consistent with the previously reported suppression of cell-mediated immune response of these animals to the original immunising antigens (Hunneyball et al., 1978b). This corroborates the findings of Goldberg et al. (1974) and Menard and Dion (1975), who showed that the production of chronic antigen-induced monoarticular arthritis was dependent on the cellmediated immune responsiveness of the animal. In addition, it has been observed (Hunneyball et al., $1978 \mathrm{~b}$ ) that the D-penicillamine treatment of normal rabbits produced an increase in the phagocytic index of the reticuloendothelial system, and that this increase varied considerably between individual animals in a similar fashion to the observed reduction of the synovitis in response to treatment with the drug.

In conclusion, it has been shown that prolonged daily oral treatment (100-200 days) of rabbits with D-penicillamine at a dose of $15-30 \mathrm{mg} / \mathrm{kg}$ can cause a reduction in the severity of chronic monoarticular arthritis in a considerable proportion of animals. It seems likely that this effect is attributable to a suppression of the cell-mediated immune response to the antigen, or possibly to a stimulation of the phagocytic activity (presumably of macrophages), or it might even result from a combination of both of these effects.

We are most grateful to Mr I. Lewin for his skilled technical assistance. We thank Dr W. H. Lyle, of Dista Products Ltd., for kindly providing the Distamine used in this study. Generous financial support from the Medical Research Council (I.M.H.) and Arthritis and Rheumatism Council G.A.S.) is gratefully acknowledged.

\section{References}

Blackham, A., and Radziwonik, H. (1977). The effect of drugs in established rabbit monoarticular arthritis. Agents and Actions, 7, 473-480. 
Consden, R., Doble, A., Glynn, L. E., and Nind, A. P. (1971). Production of a chronic arthritis with ovalbumin: its retention in rabbit knee joints. Annals of the Rheumatic Diseases, 30, 307-315.

Constable, T. J., Crockson, A. P., Crockson, R. A., and McConkey, B. (1975). Drug treatment of rheumatoid arthritis: a systematic approach. Lancet, 1, 1176-1179.

Day, A. T., Golding, J. R., Lee, P. N., and Butterworth, A. D. (1974). Penicillamine in rheumatoid disease: a longterm study. British Medical Journal, 1, 180-183.

Dumonde, D. C., and Glynn, L. E. (1962). The production of arthritis in rabbits by an immunological reaction to fibrin. British Journal of Experimental Pathology, 43, 373-383.

Glynn, L. E. (1968). The chronicity of inflammation and its significance in rheumatoid arthritis. Annals of the Rheumatic Diseases, 27, 105-121.

Goldberg, V. M., Lance, E. M., and Davis, P. (1974). Experimental immune synovitis in the rabbit. Relative roles of cell mediated and humoral immunity. Arthritis and Rheumatism, 17, 993-1005.

Hunneyball, I. M., Stewart, G. A., and Stanworth, D. R. (1977). Effect of D-penicillamine on chronic experimental arthritis in rabbits. Annals of the Rheumatic Diseases, 36, 378-380.

Hunneyball, I. M., Stewart, G. A., and Stanworth, D. R. (1978a). The effects of oral D-penicillamine treatment on experimental arthritis and the associated immune response in rabbits. 1: The effects on humoral parameters. Immuno$\log y, 34,1053-1061$.
Hunneyball, I. M., Stewart, G. A., and Stanworth, D. R는 $(1978 b)$. The effects of oral D-penicillamine treatment on? experimental arthritis and the associated immune respons in rabbits. II: The effects on cellular parameters. Immuno $\frac{\text { S }}{7}$ $\log y, 35,159-166$.

Huskisson, E. C., Gibson, T. J., Balme, H. W., Berry, H.들 Burry, H. C., Grahame, R., Hart, F. D., and Wojtulewski $\overline{\bar{s}}$ J. A. (1974). Trial comparing D-penicillamine and gold in rheumatoid arthritis. Annals of the Rheumatic Diseases? 33, 532-535.

Jaffe, I. A. (1970). The treatment of rheumatoid arthritis and necrotising vasculitis with penicillamine. Arthritis and Rheumatism, 13, 436-443.

Liyanage, S. P., and Currey, H. L. F. (1972). Failure of orat D-penicillamine to modify adjuvant arthritis or immune? response in the rat. Annals of the Rheumatic Diseases, 310 521.

Menard, H. A., and Dion, J. (1975). Experimental immune्లు arthritis: host factors. Journal of Rheumatology, 2, 373 383.

Multicentre Trial Group (1973). Controlled trial of penicillamine in severe rheumatoid arthritis. Lancet, $1_{0}$ 275-280.

Püschel, W., Rosenkranz, M., Geiler, G., Caffier, B., Stiehl, P., and Richter, V. (1976). Zur Wirkung von D-penicillamire auf die experimentelle allergische Arthritis des Kaninchens Zeitschrift für Rheumatologie, 35, 201-209.

Ratcliff, A. P., and Hardwicke, J. (1964). Estimation of serum $\overrightarrow{0}$ haemoglobin-binding capacity (haptoglobin) on Sephadex G 100. Journal of Clinical Pathology, 17, 676-679. 